\title{
Selective Thiol Detection in Authentic Biological Samples with the Use of Screen-printed Electrodes
}

\author{
Patricia T. LEE and Richard G. CoMPTON ${ }^{\dagger}$ \\ Department of Chemistry, Physical and Theoretical Chemistry Laboratory, Oxford University, South Parks \\ Road, Oxford, OX1 3QZ, UK
}

\begin{abstract}
A selective voltammetric determination of homocysteine and glutathione was applied to cell tissue culture media and human plasma via a single two-step method. The two-step method relies on the 1,4-Michael addition reaction between electro-oxidized catechol and the target thiol. Furthermore, the procedure relies on the differing reaction kinetics of the ortho-quinone with various thiol species giving different responses as a function of the scan rate. At faster scan rates homocysteine is only detected, while at slower scan rates the adduct signal reflects both homocysteine and glutathione. As a result, the quantification of both homocysteine and glutathione can be determined with a combination of both sets of data. The previous proof-of-concept (P. T. Lee, D. Lowinsohn, and R. G. Compton, Sensors, 2014, 14, 10395), is applied to the quantification of thiols in both tissue culture media and human plasma alone. Analytical parameters were determined for both homocysteine and glutathione in the respective media and the linear range. The sensitivities in tissue culture media are $c a .3 \mathrm{nA} \mu \mathrm{M}^{-1}$ and $c a .1 \mathrm{nA} \mu \mathrm{M}^{-1}$ and the limits of detections are $c a .2 \mu \mathrm{M}$ and $c a$. $1 \mu \mathrm{M}$ for homocysteine and glutathione, respectively. In human plasma, the sensitivities were determined to be 94 and $39 \mathrm{nA} \mu \mathrm{M}^{-1}$, and the limit of detections are $c a .0 .8 \mu \mathrm{M}$ and $c a .0 .8 \mu \mathrm{M}$ for homocysteine and glutathione, respectively.
\end{abstract}

Keywords Homocysteine, glutathione, catechol, human plasma, cell tissue media, carbon nanotube screen-printed electrode, thiols, 1,4-Michael addition reaction, cyclic voltammetry

(Received December 18, 2014; Accepted February 6, 2015; Published July 10, 2015)

\section{Introduction}

Biological samples such as physiological samples and/or growth media are often comprised of many constituents including amino acids, vitamins, proteins, and salts. ${ }^{1-11}$ Thiols, such as homocysteine ( $\mathrm{HCy}$ ) and glutathione (GSH), are ubiquitous in physiological fluids as they play an important role in maintenance, antioxidation protection and metabolism. ${ }^{9,12-13}$ Levels of these thiols have been reported to be important as changes at the cellular role may have implications to conditions such as arteriosclerosis, ${ }^{5,12,14}$ leukaemia, ${ }^{14-15}$ cancer, ${ }^{14,16}$ Alzheimer's, ,17-19 and/or Parkinson's disease., ${ }^{517-18}$ As such, selective detection is valuable for the biomedical community as it may provide a versatile diagnostic pathway to monitor various conditions. However, many electroanalyses of biological samples require the prior use of a separation technique as samples may contain many reactive species that may impede the electrochemical detection. ${ }^{1-2,4,8,15,17,20-24}$ This becomes a particular problem when continual and high throughput monitoring is needed.

In recent years, screen printing technology has gain popularity through its capability for mass producing electrodes. ${ }^{25-27}$ A screen-printed electrode is usually comprised of a reference electrode, a counter and a working electrode all printed on an inert substrate. ${ }^{28-29}$ Often with carbon-based screen-printed

† To whom correspondence should be addressed.

E-mail: richard.compton@chem.ox.ac.uk electrodes, the inks are comprised of graphite or carbon nanotubes which provide them with similar attributes to the conventional corresponding carbon working electrodes. ${ }^{26,30-31}$ Screen-printed electrodes are well established for being compact, low in cost, versatile, robust, and disposable. ${ }^{26,32-33}$ This in turn makes them attractive in applications that require high throughput screening without the need for complex and/or expensive equipment.

Our earlier works have shown that the electrochemical detection of thiol is possible with the use of a mediator, catechol, via a 1,4-Michael addition reaction. ${ }^{28,34}$ In a 1,4-Michael addition reaction, the electro-oxidized catechol (o-benzoquinone) undergoes a nucleophilic attack by a thiol, resulting in a new electrochemically active species..$^{12,28,34-35}$ This reaction involves a net loss of four electrons and four protons (Scheme 1); two electrons and two protons are initially required to oxidize the catechol to form the ortho-quinone. Then, the ortho-quinone can undergo a 1,4-Michael addition with the thiol regenerating back to a hydroquinone entity, for which it can be re-oxidized again with two electrons and two protons. Voltammetric evidence of this reaction typically shows an increase in the forward peak current, a decrease in the backward peak current, and the introduction of a new adduct peak that can grow with increasing thiol concentration (Scheme 1)..$^{12,28,34-35}$ The work presented in this current paper uses this reaction as the analytical basis for thiol detection.

In another report, we have also shown how to selectively detect homocysteine and glutathione in the presence of each other in a purely aqueous system using a proposed two-step 


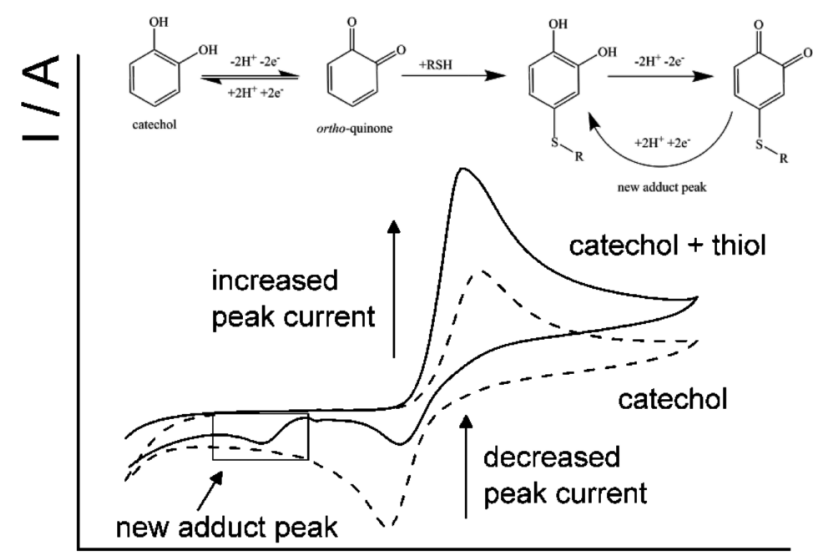

$\mathrm{E} / \mathrm{V}$

Scheme 1 Reaction pathway for the 1,4-Michael addition reaction of catechol with a thiol-containing molecule.

method. ${ }^{28}$ The single two-step method takes advantage of the different reaction rates of the homocysteine and glutathione with the electrochemically oxidized catechol with the later reacting more slowly (Scheme 2). Initially, a faster scan rate is applied, allowing a rapid reaction with homocysteine to take place, and thus 'outrunning' the reaction with glutathione. This subsequently leaves an analytically useful signal for homocysteine only detection. Next, a slower scan rate is applied that allows both analytes to react, thus relating the contents of both analytes in the adduct peak. Thereafter, the determined homocysteine concentration is subtracted from the concentration obtained at a low scan rate, and thus resulting in the concentration of glutathione. This paper reports on the adaptation of our previous proof-of-concept work applied to 'real world' samples, notably tissue cell culture media and human plasma in order to emphasize the authentic practical application and viability of this method. With the added use of disposable screen-printed electrodes, the selective detection of homocysteine and glutathione in 'real' world biological samples brings nearer realization of the notion of bringing a viable sensor to the user in the form of a point-of-care system.

\section{Experimental}

\section{Reagents and chemicals}

Catechol (99\%), glutathione (98\%), D-L-homocysteine ( $\geq 95 \%$ ), Dulbecco's Modified Eagles's Media (DMEM), and human plasma were purchased through Sigma-Aldrich at their highest purity, and were used as received without any further purification steps. All solutions were prepared with deionized water at a resistivity of no less than $18.2 \mathrm{M} \Omega \mathrm{cm}^{-1}$ at $25^{\circ} \mathrm{C}$ (Millipore, UK). Buffer solutions, $0.15 \mathrm{M}$, were prepared using potassium monohydrogen phosphate ( $\geq 98 \%$, Sigma-Aldrich), potassium dihydrogen phosphate ( $\geq 99 \%$, Sigma-Aldrich), and potassium hydroxide ( $\geq 85 \%$, Sigma-Aldrich) was used accordingly to the required $\mathrm{pH}$ range. All buffer solutions were made up with a supporting electrolyte of $0.10 \mathrm{M}$ potassium chloride (99\%, Sigma-Aldrich).

\section{Apparatus}

Electrochemical experiments involving the tissue culture media, DMEM, were carried out in a three-electrode system using a saturated calomel reference electrode (SCE) from Hach

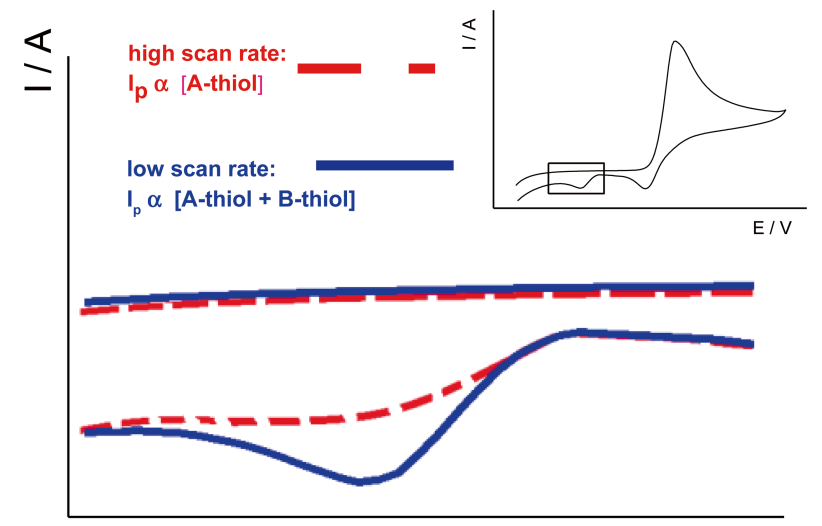

$E / V$

Scheme 2 Schematic representation of a two-step method for the selective electrochemical detection of homocysteine and glutathione at the adduct peak.

Lange, UK, a platinum mesh (99.99\%) counter electrode from Goodfellow, UK, and multi-walled carbon nanotube disposable screen-printed electrodes from DropSens, Spain to be used as the working electrode. The use of the calomel reference electrode in the tissue culture media was to ensure that all potentials are reliably comparable to that seen in earlier studies. ${ }^{28,34}$ Whereas, the silver quasi-reference electrode built into the screen-printed electrodes was prone to large variation with up to, ca. estimated $40 \mathrm{mV}$ shifts in reference potential. The three electrodes mentioned were located in a $50 \mathrm{~mL}$ cell where experiments involving tissue culture media were carried out. To ensure little to no change in the resistance, the distance among the electrodes were fixed to each other. Experiments involving human plasma were fully carried out on the screenprinted electrode due to the small quantity of available human plasma. An approximately $50 \mu \mathrm{L}$ drop of plasma sample was deposited onto the ceramic chip such that all three electrodes are covered.

All experiments were conducted using a computer-controlled potentiostat, PGSTAT 101 (ECO-chemie, NL). A temperature controlled water bath was also used to ensure that all electrochemical experiments were carried out at $20 \pm 2^{\circ} \mathrm{C}$ in a Faraday cage. All $\mathrm{pH}$ measurements were conducted using a pH213 Microprocessor pH meter from Hanna Instruments, UK. The $\mathrm{pH}$ meter was calibrated using Duracal buffers of $\mathrm{pH} 4.01$ $\pm 0.01, \mathrm{pH} 7.00 \pm 0.01$, and $\mathrm{pH} 10.01 \pm 0.01$ (Hamiliton, $\mathrm{CH}$ ).

\section{Carbon nanotube screen-printed electrode (CNT-SPE)}

Multi-walled carbon nanotube screen-printed electrodes were used in this study to further the notion of a point-of-care system for homocysteine and glutathione detection. The screen-printed electrode itself is made of a ceramic substrate consisting of $4.0 \mathrm{~mm}$ in diameter multi-carbon nanotube working electrode, a carbon counter electrode and a silver reference electrode. Prior to each experiment, a pre-treatment is performed on the disposable electrode so as to remove any possible excess silver on the working electrode as a result of the manufacturing process. ${ }^{28}$ This involves applying potential cycling from $-0.5 \mathrm{~V}$ to $+0.2 \mathrm{~V}(v s . \mathrm{MSE})$ in a $0.1 \mathrm{M}$ sodium nitrate solution for at least $20 \mathrm{~min}$. Afterwards, the electrode is rinsed with deionized water and carefully dried. The characterization of the screenprinted electrode containing the multi-walled carbon nanotube working electrode was previously performed and reported. ${ }^{28}$ 


\section{Results and Discussion}

\section{Detection in tissue culture media}

Tissue culture media contains a variety of amino acids and vitamins to help facilitate in the nourishment and maintenance of cell growth..$^{9,11}$ Some of its contents may be electro-active, and other possible interferences can arise when catechol is added to the medium. Before applying the single two-step analytical procedure (as described earlier), an investigation of possible interferences from the cell tissue culture medium was carried out. Cyclic voltammetry was utilized in $100 \%$ tissue culture media, DMEM, at a scan rate of $50 \mathrm{mV} \mathrm{s}^{-1}$ in both the absence and presence of $0.1 \mathrm{mM}$ catechol, shown in Fig. 1. The figure shows that within the potential window of interest for analysis, the media alone will not interfere with the measurement. When catechol is added to the media, a redox process at $E_{1 / 2}=$ $+0.15 \mathrm{~V}$ (vs. SCE) is observed, which corresponds to the twoelectron, two-proton oxidation of the ortho-quinone species. ${ }^{9,12,34}$ This observation of catechol is consistent with literature reports that the media alone will not interfere with the electrochemical reaction of catechol. ${ }^{12,28,34}$

Cyclic voltammetry was applied to tissue media in the presence of catechol and thiols. Figure 2 shows the voltammetric

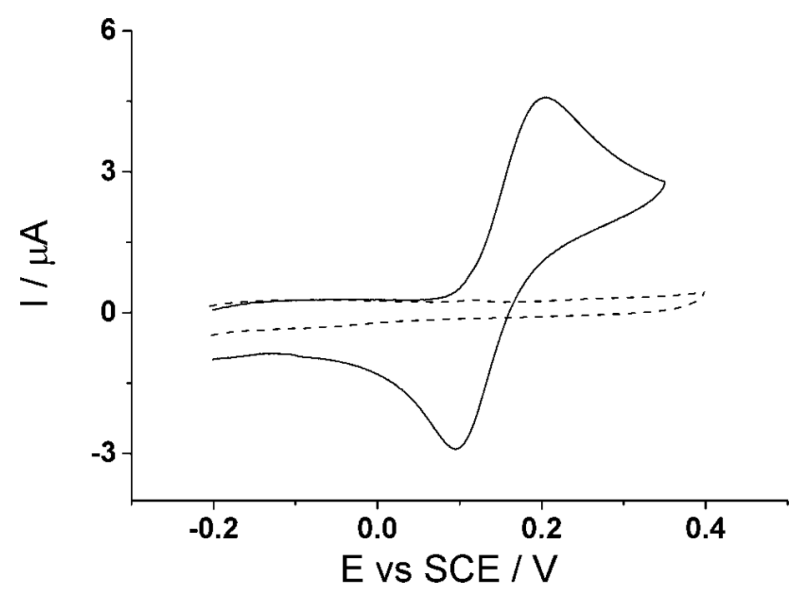

Fig. 1 Cyclic voltammograms $\left(50 \mathrm{mV} \mathrm{s}^{-1}\right)$ at a CNT-SPE in Dulbecco's Modified Eagle's Media (DMEM) in the absence (dashed line) and presence (solid line) of $0.1 \mathrm{mM}$ catechol.

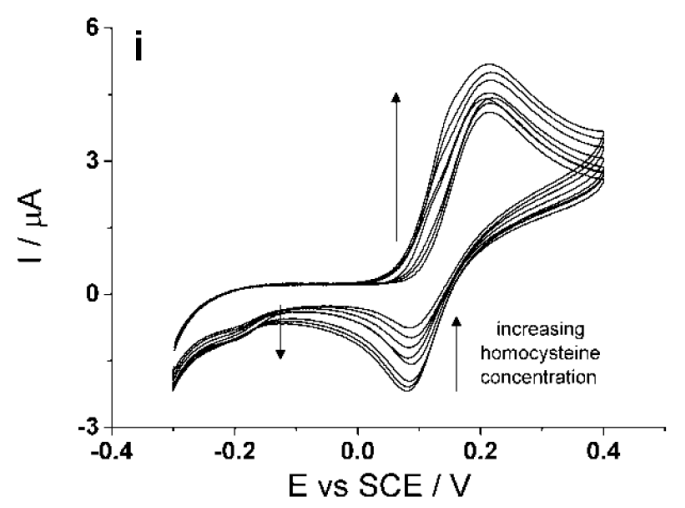

behavior at $50 \mathrm{mV} \mathrm{s}^{-1}$ of $0.1 \mathrm{mM}$ catechol for different concentrations of either homocysteine or glutathione. The figure shows that with each addition of the analyte, a new adduct peak emerges ( $c a$. $-0.2 v s$. SCE), and increases along with the forward peak, while the backward peak decreases. This is consistent with a 1,4-Michael addition reaction, as described above and elsewhere. ${ }^{9,12,28,34}$ Analytical curves were then obtained at this scan rate; specifically, the adduct peak current, $I$, was plotted against the concentration of each thiol analyte. The analytical parameters tabulated in Table 1 show a linear relationship for homocysteine at $50 \mathrm{mV} \mathrm{s}^{-1}$ is $I(\mathrm{nA})=(6.59 \pm$ $0.019)[\mathrm{HCy} / \mu \mathrm{M}](n=3)$ for concentrations of up to $20 \mu \mathrm{M}$. The limit of detection (LOD) is determined to be $c a$. (0.5 \pm 0.01) $\mu \mathrm{M}$. For glutathione, the linear relationship at the same scan rate is $I(\mathrm{nA})=(1.02 \pm 0.462)[\mathrm{GSH} / \mu \mathrm{M}](n=3)$ for concentrations ranging from 0 up to $10 \mu \mathrm{M}$; the LOD is $c a$. $(1.0 \pm 0.3) \mu \mathrm{M}$. Due to the complexity of the tissue culture media, we can expect to observe lower sensitivities for homocysteine and glutathione compared to a pure aqueous system, 19 and $1.9 \mathrm{nA} \mu \mathrm{M}^{-1}$ respectively. ${ }^{28}$ Nonetheless, the relationship among those values are consistent with their reaction rates for catechol. ${ }^{28}$ However, at a low scan rate the observed adduct peak will reflect the reaction of the electrooxidized catechol with both homocysteine and glutathione, thus making selective quantification difficult when both thiols are present in the same solution. ${ }^{28}$

An optimum scan rate of $300 \mathrm{mV} \mathrm{s}^{-1}$ was found for the homocysteine selectivity in a tissue culture media. Figure 3 shows voltammogram of the electro-oxidized catechol in the presence of glutathione (dotted line) and in the presence of homocysteine (solid line). The figure shows that in the presence of glutathione, the adduct peak ceased to exist when a faster scan rate was applied; however, the adduct peak ( $c a$. $-0.2 \mathrm{~V} v s$. SCE) appears in the presence of homocysteine. This indicates

Table 1 Analytical parameters for the detection of homocysteine and glutathione in cell tissue culture media $(\mathrm{pH} 8.0)^{\mathrm{a}}$

\begin{tabular}{lccccc}
\hline Thiol & $\begin{array}{c}\text { Scan rate/ } \\
\mathrm{mV} \mathrm{s}^{-1}\end{array}$ & $\begin{array}{c}\text { Slope/ } \\
\mathrm{nA} \cdot \mu \mathrm{M}^{-1}\end{array}$ & $R^{2}$ & $\begin{array}{c}\text { LOD/ } \\
\mu \mathrm{M}\end{array}$ & $\begin{array}{c}\text { Linear } \\
\text { range/ } \mu \mathrm{M}\end{array}$ \\
\hline Homocysteine & 300 & $(2.96 \pm 0.021)$ & 0.981 & 2 & $0-20$ \\
& 50 & $(6.59 \pm 0.019)$ & 0.997 & 0.5 & $0-20$ \\
Glutathione & 50 & $(1.02 \pm 0.462)$ & 0.994 & 1 & $0-10$ \\
\hline
\end{tabular}

a. LOD, calculated limit of detection.

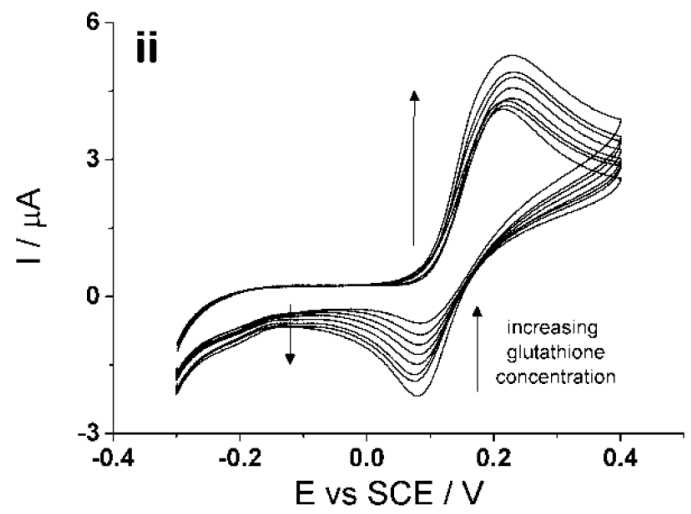

Fig. 2 Cyclic voltammograms $\left(50 \mathrm{mV} \mathrm{s}^{-1}\right)$ at a CNT-SPE of $0.1 \mathrm{mM}$ catechol (DMEM) with varying concentrations, $0-60 \mu \mathrm{M}$, of each (i) homocysteine or (ii) glutathione. 


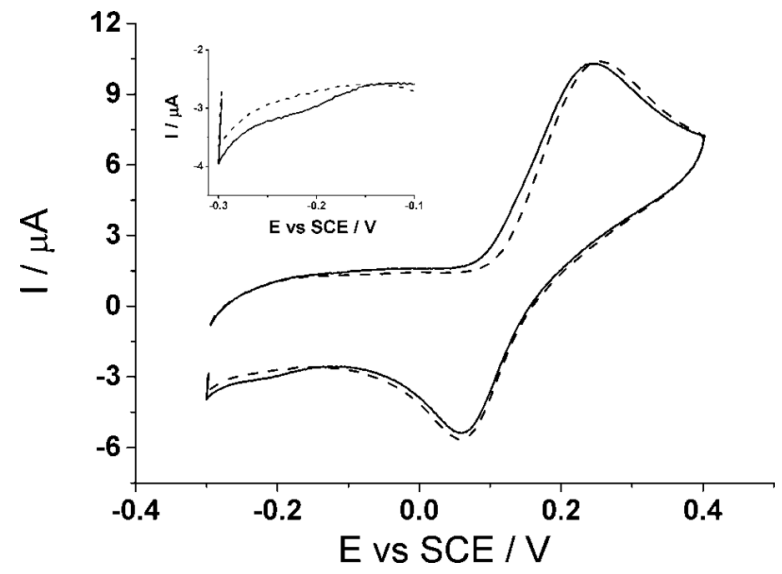

Fig. 3 Cyclic voltammograms $\left(300 \mathrm{mV} \mathrm{s}^{-1}\right)$ at a CNT-SPE in DMEM with $0.1 \mathrm{mM}$ catechol in the presence of $20 \mu \mathrm{M}$ homocysteine (solid line) and $2 \mu \mathrm{M}$ glutathione (dash line). Inset: Enlarge view of the thiol adduct peak.

that the faster scan rate 'outruns' the ortho-quinone reaction with glutathione, but is still sufficient to allow the reaction with homocysteine to take place. ${ }^{28}$ Thus perhaps the selective detection of homocysteine is achievable in the presence of glutathione in tissue culture media at the screen-printed electrode when a higher scan rate is applied. Next, a calibration curve was obtained that indicated a linear relationship of homocysteine at $300 \mathrm{mV} \mathrm{s}^{-1}, I(\mathrm{nA})=(2.96 \pm 0.021)[\mathrm{Hcy} / \mu \mathrm{M}](n=3)$, for concentrations of up to $20 \mu \mathrm{M}$, and the LOD being $c a$. $(2.0 \pm$ $0.02) \mu \mathrm{M}$ (also summarized in Table 1). Finally, at this point, all of the appropriate calibration curves have been determined, and the method can be fully applied and tested in the tissue culture media.

A number of pre-determined mixed solutions containing varying spiked amounts of homocysteine and glutathione, ranging from 1.0 to $10.0 \mu \mathrm{M}$, were examined with the presence of $0.1 \mathrm{mM}$ catechol (DMEM, $\mathrm{pH}$ 8.0) using the carbon nanotube screen-printed electrode. Upon applying the two-step method, a peak current at a scan rate of $300 \mathrm{mV} \mathrm{s}^{-1}$ was obtained from the DMEM mixture, where the homocysteine content can be determined from the analytical curve, $I(\mathrm{nA})=(2.96 \pm 0.021)$ $[\mathrm{Hcy} / \mu \mathrm{M}]$. Then by knowing the homocysteine concentration present, the peak current for homocysteine can be calculated at the low scan rate by using the analytical curve, $I(\mathrm{nA})=(6.59 \pm$ $0.019)[\mathrm{HCy} / \mu \mathrm{M}]$. Next, we can subtract this value from the total adduct peak current at a low scan rate, which results in the peak current corresponding to the reaction of glutathionecatechol. Lastly, the glutathione content can be determined from the respective calibration curve, $I(\mathrm{nA})=(1.02 \pm 0.462)$ $[\mathrm{GSH} / \mu \mathrm{M}]$. Table 2 gives the measurement results of different combinations of the thiol mixture in the tissue culture media using the two-step procedure. The table shows that the determined values correlate well within a reasonable error of the spiked thiol contents of the tissue culture media mixture. The average standard deviation for the detection measurement in comparison to the spiked values is $c a$. $10 \%$ which is acceptable for bio-molecular applications. Given that the two-step method is limited by the capacity of the fast scan rate in order for the determination of glutathione to work, the limit of detection of the procedure in tissue culture media is $c a$. $(2.0 \pm 0.02) \mu \mathrm{M}$. This value is within the range of thiols typically seen in human physiological samples. ${ }^{1,5}$ Therefore, this two-step method for quantifying homocysteine and glutathione works well in tissue
Table 2 Determination of homocysteine and glutathione in mixed solutions containing homocysteine, glutathione and $100 \mu \mathrm{M}$ catechol (DMEM, pH 8.0)

\begin{tabular}{|c|c|c|c|}
\hline \multicolumn{2}{|c|}{ Mixed solution } & \multirow{2}{*}{$\begin{array}{c}\text { Determined } \\
{\left[\begin{array}{c}\text { Homocysteine }] / \\
\mu \mathrm{M}\end{array}\right.}\end{array}$} & \multirow{2}{*}{$\begin{array}{c}\text { Determined } \\
\text { [Glutathione]/ } \\
\mu \mathrm{M}\end{array}$} \\
\hline $\begin{array}{l}\text { Homocysteine/ } \\
\mu \mathrm{M}\end{array}$ & $\begin{array}{c}\text { Glutathione/ } \\
\mu \mathrm{M}\end{array}$ & & \\
\hline 10 & 10 & $10.5 \pm 0.150$ & $9.4 \pm 1.7$ \\
\hline 10 & 5 & $9.0 \pm 0.60$ & $5.1 \pm 1.1$ \\
\hline 10 & 3 & $10.1 \pm 0.100$ & $2.1 \pm 0.10$ \\
\hline 10 & 1 & $10.9 \pm 0.800$ & $1.0 \pm 0.30$ \\
\hline 5 & 10 & $4.9 \pm 1.4$ & $10.1 \pm 0.100$ \\
\hline 3 & 10 & $2.6 \pm 0.01$ & $10.7 \pm 1.00$ \\
\hline 1 & 10 & $1.2 \pm 0.05$ & $10.4 \pm 0.250$ \\
\hline
\end{tabular}

b. Average value \pm standard deviation $(n=2)$.

Table 3 Table of some constituents of human plasma

\begin{tabular}{lccc}
\hline Constituent & Normal range & Unit & Ref. \\
\hline Aldosterone & $100-450$ & $\mathrm{pmol} / \mathrm{L}$ & $41-42$ \\
Ammonia & $0-54$ & $\mu \mathrm{mol} / \mathrm{L}$ & 41,43 \\
Aspartic Acid & $0.1-0.14$ & $\mathrm{mg} / \mathrm{mL}$ & 44 \\
Arginine & $1.5-2.5$ & $\mu \mathrm{g} / \mathrm{mL}$ & 44 \\
Calcitonin & $0-4.5$ & $\mathrm{ng} / \mathrm{L}$ & 41 \\
Cortisol & $80-700$ & $\mathrm{nmol} / \mathrm{L}$ & $45-46$ \\
Creatinine & $50-100$ & $\mu \mathrm{mol} / \mathrm{L}$ & $47-48$ \\
Cysteine & $10-30$ & $\mu \mathrm{mol} / \mathrm{L}$ & 17,38 \\
Glucose & $4.1-6.0$ & $\mathrm{mmol} / \mathrm{L}$ & 47 \\
Glutamic acid & $0.4-1.15$ & $\mu \mathrm{g} / \mathrm{mL}$ & 4,44 \\
Glutathione & $2-12$ & $\mu \mathrm{mol} / \mathrm{L}$ & $5,38,49-52$ \\
Hemoglobin & $120-160$ & $\mathrm{~g} / \mathrm{L}$ & 47 \\
Homocysteine & $5-15$ & $\mu \mathrm{mol} / \mathrm{L}$ & $1,17,38-39$ \\
Lactate & $0.5-2.22$ & $\mathrm{mmol} / \mathrm{L}$ & 47 \\
Lysine & $2.2-3.0$ & $\mu \mathrm{g} / \mathrm{mL}$ & 44 \\
Magnesium & $1.7-2.3$ & $\mu \mathrm{g} / \mathrm{mL}$ & 10,47 \\
Methionine & $0.2-1.0$ & $\mu \mathrm{g} / \mathrm{mL}$ & $21,44,53$ \\
Potassium & $12.1-25.4$ & $\mu \mathrm{g} / \mathrm{mL}$ & 47 \\
Sodium & $300-330$ & $\mathrm{mg} / \mathrm{dL}$ & 47 \\
Uric Acid & $0.18-0.48$ & $\mathrm{mmol} / \mathrm{L}$ & $54-55$ \\
Vitamin A & $30-65$ & $\mu \mathrm{g} / \mathrm{dL}$ & $56-57$ \\
Vitamin C & $23-85$ & $\mu \mathrm{mol} / \mathrm{L}$ & $58-59$ \\
Vitamin D & $20-150$ & $\mathrm{nmol} / \mathrm{L}$ & $60-62$ \\
\hline
\end{tabular}

cell culture media.

\section{Detection in human plasma}

Human plasma, itself, has a complex matrix containing different analytes and species. ${ }^{7,10}$ A partial list of constituents in human plasma is given in Table 3. Therefore, a selective determination for a specific analyte in human plasma is a challenge for the electroanalytical community, since many of its constituents may be redox active, or often impede the electroanalysis..$^{7-9,36}$ Consequently, reports that focus on electrochemical detection in human plasma are usually coupled with a separation technique, such as HPLC. ${ }^{1-2,4,8,15,17,20-23}$ In our experiments, human plasma was diluted to $25 \%$ with $0.15 \mathrm{M}$ PBS (pH 7.2), and an optimal catechol concentration of $1.0 \mathrm{mM}$ was used, because higher concentrations resulted in coagulation. Lastly, all three electrodes on the disposable screen-printed electrode, itself, were fully used due to the small quantity of available human plasma.

Initially, to investigate any interferences that may arise from 


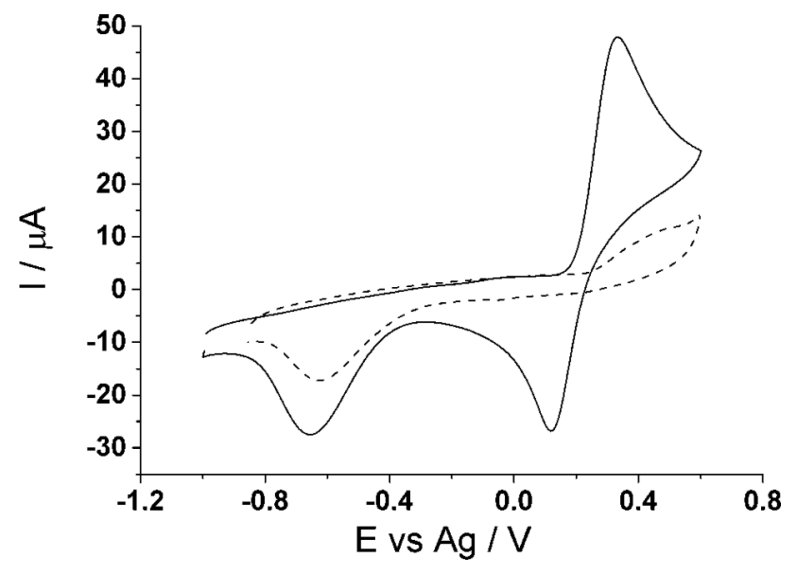

Fig. 4 Cyclic voltammogram $\left(100 \mathrm{mV} \mathrm{s}^{-1}\right)$ at a CNT-SPE in $25 \%$ human plasma diluted with $0.15 \mathrm{M}$ PBS ( $\mathrm{pH} 7.2$ ) with both the presence (solid line) and absence (dashed line) of $1.0 \mathrm{mM}$ catechol.

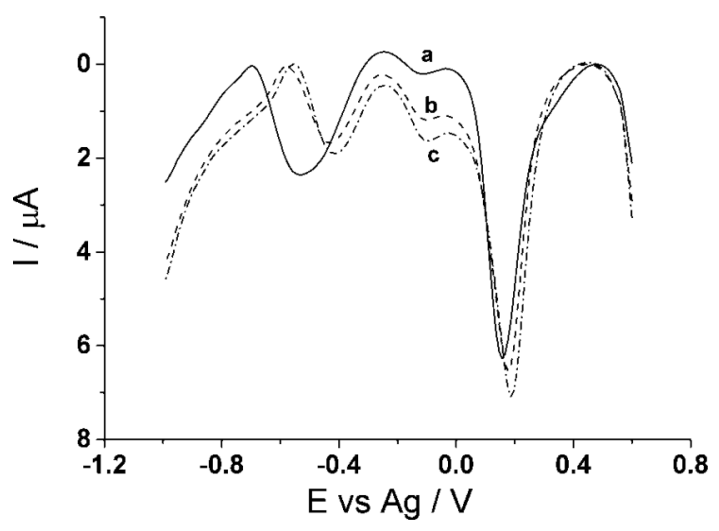

Fig. 5 Square-wave voltammograms of $25 \%$ human plasma with $1.0 \mathrm{mM}$ catechol containing a) no thiol b) $20 \mu \mathrm{M}$ homocysteine and c) $20 \mu \mathrm{M}$ glutathione (frequency, $10 \mathrm{~Hz}$; amplitude, $5.0 \mathrm{mV}$; step potential, $10 \mathrm{mV}$ ).

human plasma, itself, cyclic voltammetry was run in both the absence and presence of catechol. Figure 4 shows cyclic voltammograms $\left(100 \mathrm{mV} \mathrm{s}^{-1}\right)$ of human plasma with and without the addition of $1.0 \mathrm{mM}$ catechol (pH 7.2). This figure shows that in the absence of catechol, an anodic process occurs at $c a .+0.4 \mathrm{~V}$ (vs. $\mathrm{Ag}$ ), and a cathodic process occurrs $c a .-0.6 \mathrm{~V}$ (vs. Ag). These processes can be attributed to be a result of an unknown electroactive species in human plasma. ${ }^{5,7,37}$ With the presence of $1.0 \mathrm{mM}$ catechol in human plasma, a new redox process is observed, $E_{1 / 2}=+0.2 \mathrm{~V}$ ( $v s$. Ag), which is attributed to the two-electron redox process of the catechol forming the ortho-quinone..$^{9,12,34}$ Since analytically we are concerned with the reductive scan, the cathodic signal from the human plasma ca. $-0.6 \mathrm{~V}$ (vs. Ag) should not hinder the adduct peak signal, because the adduct signal should appear near to the catechol signal. However, because no observable thiol-catechol signal was seen in the cyclic voltammetry, the square wave was utilized to increase the sensitivity of the measurements in the plasma. Figure 5a shows a reduction scan in square-wave voltammetry (optimized to a frequency of $10 \mathrm{~Hz}$; amplitude, $5.0 \mathrm{mV}$; step potential, $10 \mathrm{mV}$ ) of human plasma containing $1.0 \mathrm{mM}$ catechol $(\mathrm{pH} 7.2)$ at the CNT-SPE. The scan rate under these optimized parameters is $100 \mathrm{mV} \mathrm{s}^{-1}$. Three signals are observed in the

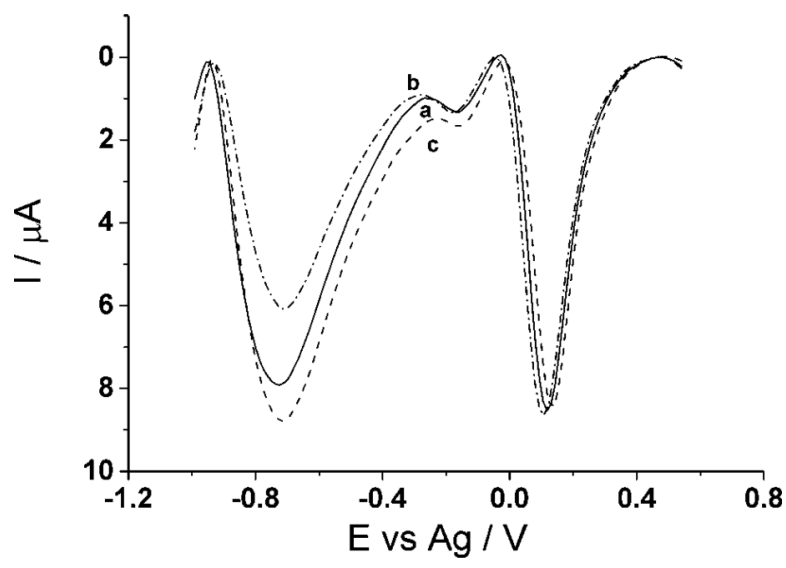

Fig. 6 Square wave voltammograms of $25 \%$ human plasma with $1.0 \mathrm{mM}$ catechol containing a) no thiol b) $20 \mu \mathrm{M}$ glutathione and c) $20 \mu \mathrm{M}$ homocysteine (frequency, $50 \mathrm{~Hz}$; amplitude, $5.0 \mathrm{mV}$; step potential, $12 \mathrm{mV}$ ).

figure corresponding to the reductive wave of the catechol ( $c a$. $+0.2 \mathrm{~V} v s . \mathrm{Ag})$, the thiol-catechol adduct peak (ca. $-0.1 \mathrm{~V} v s$. $\mathrm{Ag}$ ), and the unknown electroactive species within the plasma (ca. $-0.5 \mathrm{~V} v s$. Ag). The shift of the unknown electroactive species could be attributed to the silver quasi-reference electrode built into the screen-printed electrode. Since human plasma alone contains contents of homocysteine and glutathione, , $5,8,16,18,20,37-38$ we can expect to see an adduct peak signal associated with the thiol-catechol reaction. To definitively determine the peak observed at $c a .-0.1 \mathrm{~V}(v s$. Ag) is the thiol interaction with catechol, the human plasma was spiked with $20 \mu \mathrm{M}$ of each homocysteine and glutathione. As can be observed in Fig. 5, the peak at ca. $-0.1 \mathrm{~V}$ (vs. Ag) increases with the spiked content, thus indicating that the peak of interest represents the thiol-catechol interaction. Next, different concentrations of either homocysteine or glutathione, ranging from 0 to $20 \mu \mathrm{M}$, were added separately to the human plasma in the presence of $1.0 \mathrm{mM}$ catechol. By using square-wave voltammetry, a linear relationship, $I(\mathrm{nA})=625+(59.96 \pm$ 4.256) $[\mathrm{HCy} / \mu \mathrm{M}](n=3)$, was determined for homocysteine with a linear range of up to $15 \mu \mathrm{M}$, and the LOD was determined to be $c a$. $(0.6 \pm 0.2) \mu \mathrm{M}$. For glutathione, the linear relationship is $I(\mathrm{nA})=588+(39.1 \pm 2.22)[\mathrm{GSH} / \mu \mathrm{M}](n=3)$ within a linear range of $0-15 \mu \mathrm{M}$, and the LOD is $c a$. $(0.8 \pm 0.4) \mu \mathrm{M}$. Furthermore, square-wave voltammetry was again applied to the plasma to determine if homocysteine selectivity was possible in the presence of glutathione. The square-wave parameters were changed and the signal was optimized with a frequency of $50 \mathrm{~Hz}$, amplitude of 5.0 , and step potential of $12 \mathrm{mV}$ so as increase the scan rate to $600 \mathrm{mV} \mathrm{s}^{-1}$. Thereafter, the square wave was applied to plasma spiked with $20 \mu \mathrm{M}$ of each homocysteine and glutathione. Figure 6 shows the thiolcatechol signal, $c a$. $-0.1 \mathrm{~V}$ ( $v s$. Ag). An increase appears in the peak current in the presence of spiked homocysteine, while the peak current remains unchanged in the plasma sample spiked with glutathione, thus showing that homocysteine selectivity is possible in the human plasma sample. Once again, a calibration curve was determined for homocysteine at a higher scan rate; the linear relationship is $I(\mathrm{nA})=104+(93.7 \pm 11.4)$ $[\mathrm{HCy} / \mu \mathrm{M}](n=3)$ with a linear range of $0-15 \mu \mathrm{M}$. The LOD is ca. $(0.8 \pm 0.4) \mu \mathrm{M}$. At this point, the analytical parameters reflect the homocysteine and glutathione sourced from the human plasma sample in addition to that added. In order for the 
Table 4 Two-step method analytical parameters for the detection of homocysteine and glutathione in $25 \%$ human plasma $(\mathrm{pH} 7.2)^{\mathrm{a}}$

\begin{tabular}{cccccc}
\hline Thiol & $\begin{array}{c}\text { Scan rate/ } \\
\mathrm{mV} \mathrm{s}^{-1}\end{array}$ & $\begin{array}{c}\text { Slope/ } \\
\mathrm{nA} \cdot \mu \mathrm{M}^{-1}\end{array}$ & $R^{2}$ & $\begin{array}{c}\text { LOD/ } \\
\mu \mathrm{M}\end{array}$ & $\begin{array}{c}\text { Linear } \\
\text { range/ } \mu \mathrm{M}\end{array}$ \\
\hline Homocysteine & 600 & $(93.7 \pm 11.4)$ & 0.957 & 0.8 & $0-15$ \\
Glutathione & 100 & $(59.96 \pm 4.256)$ & 0.985 & 0.6 & $0-15$ \\
$0-15$
\end{tabular}

a. LOD, calculated limit of detection.

two-step method to be applied, the calibration curves need to be corrected so as to allow for the background signal, which is here tabulated in Table 4. The analytical parameters show the possibility for homocysteine and glutathione detection with catechol in a human plasma sample.

The two-step method for homocysteine and glutathione detection was applied to a human plasma medium using catechol at the CNT-SPE. As described above, a high scan rate of $600 \mathrm{mV} \mathrm{s}^{-1}$ was first applied to a human plasma sample also containing catechol in order to determine the homocysteine content using the corresponding analytical curve. Then, the homocysteine content could be used to determine the peak current corresponding to the low scan rate. Thereafter, the peak current associated with homocysteine at a low scan rate was subtracted from the total adduct peak at the same low scan rate. This resulted in the peak current associated with the glutathione content, which could then be calculated using the next corresponding equation. The results of the determined homocysteine and glutathione content in human plasma via two-step method are tabulated in Table 5. As described above, the limit of detection for this two-step method is dictated by the limitation of the first step, and thus the LOD for the procedure in human plasma is $(0.8 \pm 0.4) \mu \mathrm{M}$. This value is reasonable and practical for the range thiols that are typically seen in human plasma. ${ }^{1-2,5,18,39}$

The standard addition method was also performed on the plasma sample in the presence of $1.0 \mathrm{mM}$ catechol $(\mathrm{pH} 7.2)$. Using the square-wave parameters (frequency, $10 \mathrm{~Hz}$; amplitude, $5.0 \mathrm{mV}$; step potential, $10 \mathrm{mV}$ ) the human plasma was spiked separately with either homocysteine or glutathione at different concentrations of up to $20 \mu \mathrm{M}$. Then, a calibration curve of those multiple additions was used to calculate the unknown analytes concentration. ${ }^{40}$ The results from the standard addition are also tabulated in Table 5, where they can be compared to those obtained via the two-step method. The table shows that the values are in good agreement with one another, and are well within the deviation of each other, which further validates the application of the two-step method in such biological samples. The average error of the two-step method when compared to the standard addition method is $\mathrm{ca}$. $10 \%$, which is acceptable for biological applications. These results of 'real' world sample offer good promise for using the two-step method. It encourages a fast, simple, facile method towards bio-applications in the selective determination of homocysteine and glutathione.

\section{Conclusions}

We have established a successful adaptation of the single twostep method for the selective detection of homocysteine and glutathione in two 'real' world biological samples. The parameters for the simple two-step method were optimized for
Table 5 Determination of homocysteine and glutathione in $25 \%$ human plasma via a two-step procedure compared to a standard addition $^{\mathrm{b}}$

\begin{tabular}{lcc}
\hline \multicolumn{1}{c}{ Thiol } & $\begin{array}{c}\text { Standard addition } \\
\text { method/ } \mu \mathrm{M}\end{array}$ & $\begin{array}{c}\text { Two-step } \\
\text { method/ } \mu \mathrm{M}\end{array}$ \\
\hline $\begin{array}{l}\text { Homocysteine } \\
\text { Glutathione }\end{array}$ & $10.4 \pm 0.70$ & $11.1 \pm 1.40$ \\
& $15.0 \pm 0.90$ & $16.7 \pm 1.80$ \\
\hline
\end{tabular}

b. Average value \pm standard deviation $(n=3)$.

applications in both tissue culture media and human plasma using disposable carbon screen printed electrodes. The limit of detection for the system in cell tissue media and human plasma is $c a .2 \mu \mathrm{M}$ and $c a$. $1 \mu \mathrm{M}$, respectively, and with an average error of $c a .10 \%$ when compared to control experiments for either biological sample. These values are acceptable for bio-molecular applications, and may allow for the development of a at point-of-care diagnostic system for medical use.

\section{References}

1. T. Fiskerstrand, H. Refsum, G. Kvalheim, and P. M. Ueland, Clin. Chem., 1993, 39, 263.

2. P. M. Ueland, H. Refrum, S. P. Stabler, M. R. Malinow, A. Andersson, and R. H. Allen, Clin. Chem., 1993, 39, 1764.

3. D. J. VanderJagt, P. J. Garry, and H. N. Bhaganvan, Am. J. Clin. Nutr., 1987, 46, 290.

4. Y. V. Tcherkas and A. D. Denisenko, J. Chromatogr. A, 2001, 913, 309.

5. W. A. Kleinman and J. P. Richie, Biochem. Pharm., 2000, $60,19$.

6. C. J. Boushey, S. A. A. Beresfore, G. S. Omenn, and A. G. Motulsky, JAMA, J. Am. Med. Assoc., 1995, 274, 1049.

7. M. Filella, N. Belzile, and Y.-W. Chen, Crit. Rev. Environ. Sci. Technol., 2013, 43, 2071.

8. F. Michelet, R. Gueguen, P. Leroy, M. Wellman, A. Nicolas, and G. Siest, Clin. Chem., 1995, 41, 1509.

9. N. S. Lawrence, J. Davies, and R. G. Compton, Talanta, 2001, 53, 1089.

10. H. A. Krebs, Annu. Rev. Biochem., 1950, 19, 409.

11. J. Kruid, R. Fogel, and J. Limson, Electrochim. Acta, 2014, $128,41$.

12. E. H. Seymour, S. J. Wilkins, N. S. Lawrence, and R. G. Compton, Anal. Lett., 2002, 35, 1387.

13. A. Meister and M. E. Anderson, Ann. Rev. Biochem., 1983, 52,711 .

14. P. C. White, N. S. Lawrence, J. Davis, and R. G. Compton, Electroanalysis, 2002, 14, 89.

15. H. Refsum, F. Wesenberg, and P. M. Ueland, Cancer Res., 1991, 51,828 .

16. J. C. Harfield, C. Batchelor-McAuley, and R. G. Compton, Analyst, 2012, 137, 2285.

17. A. Pastore, R. Massoud, C. Motti, A. L. Russo, G. Fucci, C. Cortese, and G. Federici, Clin. Chem., 1998, 44, 825.

18. O. Nekrassova, N. S. Larence, and R. G. Compton, Talanta, 2003, 60, 1085.

19. W. Wang, J. O. Escobedo, C. M. Lawrence, and R. M. Strongin, J. Am. Chem. Soc., 2003, 126, 3400.

20. J. L. D'Erarno, A. E. Finkelstein, F. O. Boccazzi, and O. Fridman, J. Chromatogr. B, 1998, 720, 205.

21. P. Houze, S. Gamra, I. Madelaine, B. Bousquet, and B. Gourmel, J. Clin. Lab. Anal., 2001, 15, 144. 
22. S. Melnyk, M. Pogribna, I. Pogribny, R. J. Hine, and S. J. James, J. Nutr. Biochem., 1999, 10, 490.

23. R. Saetre and D. L. Rabenstein, Anal. Biochem., 1978, 90 , 684.

24. N. S. Lawrence, E. L. Beckett, J. Davis, and R. G. Compton, Anal. Biochem., 2002, 303, 1.

25. S. A. Wring and J. P. Hart, Analyst, 1992, 117, 1215.

26. J. Wang and M. Musameh, Analyst, 2004, 129, 1.

27. N. Thiyagarajan, J. Chang, K. Senthilkumar, and J. Zen, Electrochem. Commun., 2014, 38, 86.

28. P. T. Lee, D. Lowinsohn, and R. G. Compton, Sensors, 2014, 14, 10395.

29. DropSens.

30. J. Wang, Electroanalysis, 2005, 17, 7 .

31. R. W. Murray, A. G. Ewing, and R. A. Durst, Anal. Chem., 1987, 59, 379A.

32. R. C. Carvalho, A. Mandil, K. P. Prathish, A. Amine, and C. M. A. Brett, Electroanalysis, 2013, 25, 903.

33. H. D. Goldberg, R. B. Brown, D. P. Liu, and M. E. Meyerhoff, Sens. Actuators, B, 1994, 21, 171.

34. P. T. Lee, D. Lowinsohn, and R. G. Compton, Analyst, 2014, 139, 3755.

35. P. C. White, N. S. Lawrence, J. Davis, and R. G. Compton, Anal. Chim. Acta, 2001, 447, 1.

36. O. Nekrassova, P. C. White, S. Threlfell, G. Hignett, A. J. Wain, N. S. Lawrence, J. Davis, and R. G. Compton, Analyst, 2002, 127, 797.

37. D. P. Jones, J. L. Carlson, J. V. C. Mody, J. Cai, M. J. Lynn, and J. P. Sternberg, Free Radical Biol. Med., 2000, 28, 625.

38. M. A. Mansoor, A. M. Svardal, and P. M. Ueland, Anal. Biochem., 1992, 200, 218.

39. H. Refsum, P. D. Ueland, P. Nygård, and S. E. Vollset, Annu. Rev. Med., 1998, 49, 31.

40. D. A. Skoog, D. M. West, F. J. Holler, and S. R. Crouch, "Fundamental of Analytical Chemistry", 8th ed., 2003, Brooks/Cole-Thomson Learning, USA.

41. National Health Service (NHS).

42. P. J. Taylor, D. P. Cooper, R. D. Gordon, and M. Stowasser,
Clin. Chem., 2009, 55, 1155

43. J. A. Jacquez, J. W. Poppell, and R. Jeltsch, J. Appl. Physiol., 1959, 14, 255.

44. W. H. Stein and S. Moore, J. Biol. Chem., 1954, 211, 915.

45. F. K. Trefz, D. J. Byrd, and W. Kochen, J. Chromatogr. A, 1975, 107, 181.

46. J. H. M. Van den berg, C. R. Mol, R. S. Deelder, and J. H. H. Thijssen, Clin. Chim. Acta, 1977, 78, 165.

47. D. Weatherby and S. Ferguson, "Blood Chemistry and CBC Analysis", 1st ed., 2002, Bear Mountain, USA.

48. R. Achari, M. Mayersohn, and K. A. Conrad, J. Chromatogr. Sci., 1983, 21, 278.

49. S. M. Deneke and B. L. Fanburg, Am. J. Physiol., 1989, 257, L163.

50. A. Pastore, G. Federicia, E. Bertinib, and F. Piemonteb, Clin. Chim. Acta, 2003, 333, 19.

51. M. Reid and F. Jahoor, Curr. Opin. Clin. Nutr., 2001, 4, 65.

52. H. Sies, Free Radical Biol. Med., 1999, 27, 916.

53. D. E. Cole, D. C. Lehotay, and J. Evrovski, Clin. Chem., 1998, 44, 188.

54. B. N. Ames, R. Cathcart, E. Schwiers, and P. Hochstein, Proc. Natl. Acad. Sci. U. S. A., 1981, 78, 6858.

55. S. Tan, R. Radi, F. Gaudier, R. A. Evans, A. Rivera, K. A. Kirk, and D. A. Parks, Pediatr. Res., 1993, 34, 303.

56. M. Kanai, A. Raz, and D. S. Goodman, J. Clin. Invest., 1968, 47, 2025.

57. F. R. Smith and D. S. Goodman, J. Clin. Invest., 1971, 50, 2426.

58. D. Brubacher, U. Mosher, and P. Jordan, Int. J. Vitam. Nutr. Res., 2000, 70, 225.

59. M. Levine, S. J. Padayatty, and M. G. Espey, Adv. Nutr. 2011, 2, 78.

60. R. W. Gray, D. R. Wilz, A. E. Caldas, and J. Lemann, Jr., J. Clin. Endocrinol. Metab., 1977, 45, 299.

61. P. W. Lambert, B. J. Syverson, C. D. Arnaud, and T. C. Spelsberg, J. Steroid Biochem., 1977, 8, 929.

62. T. C. B. Stamp and J. M. Round, Nature, 1974, 247, 563. 